Revista Iberoamericana, Vol. LXXX, Núm. 247, Abril-Junio 2014, 353-371

\title{
UNA NARRATIVA ENTRE LA UTOPÍA Y LA DERROTA. LITERATURA Y POLÍTICA EN EL FIN DEL MILENIO
}

\author{
POR \\ Ana María Amar Sánchez \\ University of California-Irvine
}

¿Cómo se sobrevive a una derrota? ¿Cómo vivir entre los vencedores? ¿Cómo mantener la memoria viva luego de la pérdida? Las literaturas española y latinoamericana han buscado dar respuestas a estos interrogantes, se han ocupado de diversas derrotas políticas y han representado distintas alternativas para sobrevivir a ellas: resistir, enfrentar, replegarse, aceptar la pérdida, rechazarla, unirse al vencedor, olvidar. ${ }^{1}$ Un extenso corpus de relatos latinoamericanos ha debatido en las últimas décadas y el comienzo del nuevo milenio acerca de cómo pensar un pasado traumático, cómo sobrevivir a él en las actuales condiciones políticas y cómo adaptarse (o no) a los nuevos tiempos. Esta narrativa parece ofrecer diversas opciones -muy distantes en la mayoría de los casos de las soluciones simplificadoras de los discursos políticos y mediáticos- al dilema producido por el trauma de las derrotas políticas: respuestas que van desde la resistencia y el repliegue, hasta el desencanto, la asimilación y la transacción con esas nuevas condiciones históricas. Los perdedores, los derrotados políticos, son el objeto de este trabajo: el perdedor y las múltiples opciones que se abren a partir de la derrota. Esta figura interesa en tanto resultado, como imagen que anuda el episodio de la pérdida a un después: ¿qué caminos tomar cuando se es el derrotado? ¿Qué proyectos construir sobre las ruinas de lo destruido y soñado? Las formas de sobrevivir en ese después -adaptándose, resistiendo, traicionando, olvidando- anudan diferentes problemas y muchas preguntas en torno a cómo cada elección implica una política inevitablemente ligada a una postura ética. El corpus trabajado -relatos latinoamericanos y españoles de los últimos cuarenta años- representa un abanico de alternativas, de modos de relación con el vencedor, con la victoria de los otros. ${ }^{2}$ Se podría decir que muchos de ellos

1 Este trabajo forma parte de mi libro Instrucciones para la derrota. Narrativas éticas y políticas de perdedores, se enfoca en algunos aspectos teóricos allí desarrollados y se concentra en una parte del corpus analizado.

2 El corpus utilizado incluye, entre otros, los siguientes textos: El jardín de al lado de José Donoso, El viaducto de Darío Oses, El oído absoluto de Marcelo Cohen, Manual de perdedores y La mujer ducha de Juan Sasturain, Villa de Luis Gusmán, Héroes convocados de Paco I. Taibo II, Los rojos de ultramar 
proponen casi un programa de acción de algún modo utópico y divergente del que ha predominado en el mundo real; es decir, se inclinan por una propuesta ético-política en la medida en que cuestionan ciertas formas de resolver la derrota y privilegian vías de acción que implican un rechazo y una crítica a otros discursos del ámbito político y de los medios masivos. Un ejemplo paradigmático son los años noventa en la Argentina: durante el menemismo se ahondó de forma notable la discrepancia entre los discursos oficiales -triunfalistas y a favor del olvido- y el de la literatura.

Si bien mi interés por los perdedores surgió a partir de la escritura y la experiencia histórica deAmérica del Sur, no se redujo a ella. La derrota es común a diversas coyunturas históricas y no se limita a las dictaduras del Cono Sur: la pérdida de las ilusiones de los años sesenta en México, la particular situación puertorriqueña, el franquismo, pueden contarse como formas diversas de la experiencia “perdedora”. En este sentido, mi trabajo no tuvo como centro la llamada "narrativa de la dictadura", sino textos que se preguntan por las formas en que se asume una derrota política. El objetivo del estudio fue analizar cómo la literatura ha representado la situación del perdedor (y del vencedor), qué tipo de estrategias para sobrevivir propone, qué imágenes de ellos construye. De algún modo, el proyecto fue trazar un mapa que numerosos textos han construido en torno a esta experiencia: textos que parecen hacer "un recuento de los hechos" luego de la pérdida, pero que también sugieren formas de resistencia o sobrevivencia. Es interesante que sea la literatura el discurso del presente que más claramente ha debatido a través de la ficción sobre un mundo marcado por las derrotas y por el triunfalismo de los gobiernos posdictatoriales, neoliberales y corruptos.

Mi enfoque distingue a los perdedores o derrotados de los fracasados; la literatura se ha ocupado con frecuencia de este último tipo de antihéroes sin esperanzas, condenados a destinos sórdidos, al fracaso y una soledad irreversible; son paradigmáticos los relatos de Onetti con protagonistas en los márgenes del sistema social. Este tipo de fracasados no tiene casi nunca anclaje político preciso y es una figura "en el borde" de la sociedad. Los perdedores que originaron el presente trabajo, por el contrario, encarnan conductas que responden en el campo de la ficción a pérdidas políticas producidas en puntuales coyunturas históricas. Esta diferencia será crucial y abre un abanico de posibilidades: novelas centradas en el héroe -o antihéroe- resistente, en el traidor, en el vencedor, en el fracasado que ha transigido o se ha resignado, incluso narraciones cuya enunciación se inclina decididamente por los ganadores o la ambigüedad de los desencantados. El pasaje por textos tan diversos despliega entonces distintas “lógicas de la pérdida”: desde

de Jordi Soler, Nunca segundas muertes de Omar Prego Gadea, "Deutsches requiem” de Jorge Luis Borges, Sol de medianoche de Edgardo Rodríguez Juliá, La neblina del ayer de Leonardo Padura. Entre los españoles: La voz dormida de Dulce Chacón, Los girasoles ciegos de Alberto Méndez, Beltenebros de Antonio Muñoz Molina, El lápiz del carpintero de Manuel Rivas, El pianista de Manuel Vázquez Montalbán, El vano ayer de Isaac Rosa.

Revista Iberoamericana, Vol. LXXX, Núm. 247, Abril-Junio 2014,
ISSN 0034-9631 (Impreso) 
los relatos de derrotados éticos a los de perdedores desencantados; los primeros proponen el resistir y el repliegue como única alternativa digna, es decir, sugieren una solución de algún modo utópica, puesto que proporcionan un modo particular de consuelo al lector abriendo un espacio de espera hacia el futuro. A su vez, los segundos, su contracara en tanto cuestionan el sentido de persistir en sus convicciones, establecen una distopía que no deja de ser su complemento, dado que toda utopía arrastra inevitablemente su contra-utopía.

Lo que llamo "la orgullosa aceptación” de la derrota en los primeros está lejos de la resignación del vencido; por el contrario, la convicción que sostiene su no ceder, los ubica en un presente de resistencia, muy conscientes de participar en una clase peculiar de triunfo, en un triunfo ético. En este sentido disiento de la posición de Idelber Avelar en su trabajo Alegorías de la derrota; el crítico lee derrota como un fracaso que requiere de la elaboración de un duelo; es decir, no parece ver estas ficciones como formas imaginarias de resolver la pérdida. ${ }^{3} \mathrm{El}$ corpus aquí trabajado propone otras alternativas: antes bien parece plantear, en tanto escritura, en tanto parte de un discurso específico, alternativas y debates, otros usos de la política, a contrapelo de los discursos oficiales y mediáticos. Los textos son lecturas de la vida en derrota permanente y, por lo tanto, no se plantean la ausencia definitiva de lo perdido, sino la vida con esa presencia, la vida después de la pérdida, la vida hacia un futuro en el que queda para siempre la huella, la marca, de la tragedia. En la actitud de estos personajes perdedores se puede reconocer el resistir como proyecto: se resiste para algo, para perdurar y rechazar un presente con miras a un futuro. Estos antihéroes han optado por la retirada, por la renuncia a la participación, son el revés del héroe clásico, del triunfador convencido de su victoria. Su conducta recuerda la definición de Edward Said de los intelectuales como exilados, nunca plenamente adaptados, cerca de un margen, manteniéndose en una relación de exterioridad con respecto al ámbito en el que se mueven: individuos en desacuerdo con la sociedad en que viven y por lo mismo marginales y exilados en lo que se refiere a privilegios, poder y honores.

Es Adorno quien plantea con más claridad esta posición prescindente frente al poder del vencedor propuesta por la ficción. En su Minima moralia. Reflexiones desde la vida dañada afirma: "para el intelectual es la soledad inviolable el único estado en el que aún puede dar alguna prueba de solidaridad. Toda la práctica, toda la humanidad del trato y la comunicación es mera máscara de la tácita aceptación de lo inhumano” (34). Y también en él se encuentra la posibilidad de vincular al perdedor con el exilado: "Todo intelectual en el exilio, sin excepción, lleva una existencia mutilada. [...] Vive en un entorno que tiene que resultarle incomprensible [...] siempre estará desorientado” (37). Esta frase

3 Avelar considera que la literatura se hace cargo de "la necesidad no sólo de elaborar el pasado, sino también de definir su posición en el nuevo presente instaurado por los regímenes militares” y esto tiene como resultado “el imperativo del duelo” (315).

Revista Iberoamericana, Vol. LXXX, Núm. 247, Abril-Junio 2014, $353-371$
ISSN 0034-9631 (Impreso) 
recuerda al lector algunos personajes como el Tardewski de Respiración artificial, el detective Conde en La neblina del ayer, el Echenique de Manual de perdedores: todos se encuentran en un margen, “desterritorializados", en alguna forma de exilio con respecto a la sociedad y al sistema en el que viven; a la vez, poseen una aguda conciencia de ese distanciamiento y han hecho de ese desapego un valor y una práctica ético-política.

Esta postura distanciada, ese proyecto de no connivencia o participación en el poder, la elección del margen, no como desinterés o pasividad sino como resistencia, como única acción válida, podría hacer pensar en una anulación voluntaria de toda intervención en la política activa. ¿Cómo lograr entonces incidir en el Estado? ¿Qué posibilidades hay de influir, cambiar, lograr lo deseado si se lo rechaza y se insiste en permanecer apartado? Es habitual pensar el poder ligado a un centro, lejos de cualquier marginalidad; en especial, cuando se trata del poder político, éste queda asociado al Estado y a sus instituciones que son por definición su espacio de pertenencia inevitable. De ahí, los reparos a los perdedores de estas ficciones con respecto a su posible eficacia política: parecen ser figuras éticas, paradójicamente utópicas y sin posibilidad alguna de verdadera acción. Sin embargo, su posición no está lejos de otros discursos con los que se viene pensando lo político en el presente. A partir de Foucault, sabemos, se puede considerar el poder desde otra perspectiva y no como un fenómeno de dominación -compacto y homogéneo-. El lugar de la resistencia es ya en sí mismo un espacio de poder: “donde hay poder hay resistencia [...] ésta nunca está en posición de exterioridad [...] Se está necesariamente 'en' el poder, no es posible escapar de él” (113). Es decir, la postura de los personajes perdedores es también un lugar de poder -de mucho poder-: su rechazo a la participación representa un forma no menor de ejercerlo y en tensión con diversas manifestaciones tradicionales de ese poder.

La "retirada" de los perdedores, su rechazo a las opciones tradicionales de la política "tal como es”, su búsqueda de una posición diferente -en el "margen”-, nos lleva a relacionar esta narrativa con discusiones muy actuales en torno a la política, el poder, la ética y la memoria. Es decir, se pueden leer en estos relatos, dramatizados a través de sus protagonistas, vínculos con reflexiones que buscan "otra política posible"; van en el mismo sentido en que lo hacen los trabajos de Giorgio Agamben, Alain Badiou, Roberto Esposito, Michel Onfray, Jacques Rancière. Podría sostenerse que los ensayos teóricos y los textos ficcionales coinciden en el intento de repensar la política-alejándose de las posturas que la unen indisolublemente al Estado.

Como sabemos, la llamada “caída de las utopías" representó una profunda crisis, en los años ochenta y noventa, de las categorías con las que se construyeron los proyectos políticos de los sesenta y setenta; la degradación que sufrió la práctica política -en especial, pero no únicamente, en América Latina- en años de triunfo e impunidad de diversas clases de "vencedores" produjo desencanto y llevó a la pérdida del sentido mismo de la política y la ética como campos de reflexión y praxis simultáneos. En

Revista Iberoamericana, Vol. LXXX, Núm. 247, Abril-Junio 2014, $353-371$
ISSN 0034-9631 (Impreso) 
este contexto, el "retorno" de ambas sin duda está relacionado con el fracaso evidente de las posiciones triunfalistas y cínicas de los años noventa, cuando la noción se hace progresivamente borrosa y predomina la sensación de 'muerte de la política'. Ese desencanto que caracterizó la última década del siglo xx profundizó la incredulidad en ella y, aún más, en la posibilidad de un nexo real con la ética; ha prevalecido una mirada que distingue de modo tajante la política tal como es de cómo debería ser.

Asimismo, para toda la tradición del siglo xx, hablar de política supone hablar del Estado; la identificación entre ambos términos implica lo que podría llamarse una relación "trabada": el estado es una institución política y se afirma que lo político se define como la acción del Estado. Los debates tienen un punto de partida inevitable, una referencia clásica: El concepto de lo político de Carl Schmitt que, escrito bajo el impacto de los resultados de la primera guerra y la derrota de Alemania, suele leerse como una respuesta a la pérdida de autoridad del Estado producida durante la República de Weimar. La definición que da un estudioso de la política como Norberto Bobbio expone con mucha claridad la idea que primó sobre ella durante el siglo xx:

entendida como forma de actividad o de praxis humana, aparece estrechamente relacionada con el de poder [...] Existen diferentes formas de poder del hombre sobre el hombre [...] El poder político es en toda sociedad de desiguales el poder supremo, es decir, el poder al que todos los demás aparecen, de alguna forma, subordinados. (177-179)

A este dominio, o exclusividad sobre la fuerza, se refieren muchos ensayos desde Max Weber, quien analiza el estrecho vínculo entre política y violencia: “Actualmente la relación entre el Estado y la violencia es particularmente íntima [...] 'Política’ significa para nosotros el esfuerzo por compatir el poder o por influir en su distribución, ya sea entre los Estados, o en el interior del Estado" (66).

La necesidad de repensar la política, de buscar nuevas respuestas al descrédito y al desgaste de sus prácticas tradicionales, encuentra en los ensayos de los teóricos antes mencionados un espacio de debate esencial: en ellos se señala el fracaso radical de toda política asimilada al Estado. Todos intentan nuevos caminos para el ejercicio de una práctica desprendida de su ligazón con el poder, proponen "reinventar la política", establecer otro lugar y otras prácticas para su ejercicio, fuera y en contra del Estado: Esposito plantea su controversial noción de lo impolítico como una radicalización de lo político en tanto la política es conflicto, "negación de cualquier tipo de conjunción entre el bien y el poder" (Categorías 15). Por su parte, Rancière diferencia política de policía, ésta es el terreno que le pertenece al gobierno, cuya función es organizar y establecer jerarquías; la comunidad es el centro del litigio permanente entre ambas, es decir, la política surge cuando los excluidos, que no son contados como parte social, instauran el conflicto. A su vez, Agamben centra su reflexión en las figuras del refugiado y el estado de excepción, como resultado de "la imparable decadencia del

\footnotetext{
Revista Iberoamericana, Vol. LXXX, Núm. 247, Abril-Junio 2014, 353-371 ISSN 0034-9631 (Impreso) ISSN 2154-4794 (Electrónico)
} 
Estado-nación y la corrosión general de las categorías jurídico-políticas tradicionales” (21). Posiblemente sea el análisis de Badiou el que establece un vínculo más estrecho con las representaciones de muchos de los textos estudiados. Su noción de una nueva política implica una política sin partido, que pretende ser, al mismo tiempo, una ética; restituye así el vínculo entre ambas a partir de pensar la primera sustraída del estado, dado que "en las políticas de representación no puede haber ética, pues, para un sujeto, la acción ética es justamente aquella que no puede ser delegada ni representada. En la ética, el sujeto se presenta él mismo, decide él mismo, declara lo que él quiere en su propio nombre" (Reflexiones 32). Por lo tanto, esta política es para el filósofo francés "un pensamiento que no quiere ocupar el Estado, sino forzarlo a hacer esto o aquello" (Reflexiones 33), no es una actividad ligada al poder ni se rige por un principio de interés como las vinculadas con el Estado.

Sorprende la notable conexión entre este modo de concebir lo político y las conductas que asumen los protagonistas de los relatos del corpus; en especial los perdedores éticos, por su resistencia, su no ceder a la demanda de la política convencional y triunfalista del Estado, parecen la puesta en práctica de las teorías mencionadas. La exploración teórica corre paralela y en el mismo sentido a la de los textos literarios: éstos también prueban otras formas de pensar la acción política, los personajes se alejan del Estado y sus instituciones, asumen un espacio reticente a la acción. Relatos y teoría van a contrapelo de las prácticas vigentes en la política en uso; parecen “ensayar” las propuestas teóricas que buscan reinventar de modo radical una política futura.

Los protagonistas en las novelas del corpus ligan, a su vez, una ética de la convicción a una forma especial de "hacer política" con la que se juegan a la recuperación de la memoria, buscan recordar en un mundo en el que la mayoría de los discursos está empeñada en lograr el olvido. En esta capacidad de evocación se cifra parte de la actitud ética del perdedor: tener presente el pasado significa no aceptar el fracaso o la adaptación, resistir ante el nuevo estado de cosas. Es por eso que no puede pensarse la resistencia y la "retirada", ese permanecer al margen, como una actitud pasiva; la voluntad de memoria es lo que le permite también confrontarse y diferenciarse de los perdedores que han pactado, se han adaptado o han traicionado y optaron por el olvido. Si el mundo del presente funciona en base a la cultura de la “amnesia”, la despolitización de la vida y la falta de memoria, la recuperación del pasado de los vencidos se convierte en un hecho político y ético. Muchos de los protagonistas y narradores sostienen su dignidad negándose tercamente a olvidar, afirmándose como perdedores; esa tensión entre su recuerdo y la desmemoria del vencedor crea el problemático espacio en que se mueven estos derrotados. En este sentido, su conducta sigue los mismos parámetros propuestos por Michel Onfray quien denomina principio de Antígona al empecinamiento ético

Revista Iberoamericana, Vol. LXXX, Núm. 247, Abril-Junio 2014, $353-371$
ISSN 0034-9631 (Impreso) 
que no acepta complicidades con el poder. ${ }^{4}$ En su notable trabajo sobre lo que llama “el rebelde” o "el libertario”, Onfray define una estrategia que puede asimilarse con la de los personajes analizados: se trata de "desalojar al poder de donde se encuentre, circunscribirlo, rodearlo, esquivarlo”. Se trata de instalar

la ética y la política sobre el perpetuo terreno de la resistencia [...] Resistir, es decir, nunca colaborar, nunca ceder, guardar para sí todo lo que hace la fuerza, la energía y la potencia del individuo que dice no a todo lo que apunta a [...] la desaparición de su identidad. [...] Los rebeldes que colocan su orgullo muy por encima de las prebendas ofrecidas por la colaboración con los poderes establecidos. (184-185, énfasis del autor)

Pensar la ética política del perdedor nos remite a un amplio corpus en el que los textos del mexicano Paco Ignacio Taibo II constituyen un ejemplo excepcional, tanto los ficcionales como los ensayísticos, todos indudablemente políticos. ${ }^{5}$ Una frase en el prólogo a su colección de biografías Arcángeles. Doce historias de revolucionarios herejes del siglo $X X$ podría encabezar muchos de los relatos analizados: "En medio de tanto culto a la victoria, éstas son historias de tremendas y no por ello menos heroicas derrotas. Historias que tienen que ver con la tenacidad, el culto a los principios, la política entendida como moral trágica y terrible”. A su vez, su colección de notas, ensayos y cuentos Primavera pospuesta se abre con la siguiente cita: “Al fin, que yo sólo soy un poco de lo que tú fuiste: el heredero de gente derrotada” (7). En este caso ya no se trata de la representación de un antihéroe ficcional o de un personaje histórico, sino que es el mismo Taibo el que opta por ese espacio para configurar su condición de intelectual mexicano. En ese epígrafe establece una filiación, una herencia que se refiere tanto a su padre, Taibo I, escritor y exilado español, ${ }^{6}$ como a sus “padres” literarios ${ }^{7}$ a los que se alude en muchas de las notas y artículos de la colección que, por otra parte, tiene como subtítulo “Una versión personal de México en los 90”. En esta “herencia de gente

4 Antígona es una figura recurrente cuando quiere señalarse la diferencia entre una ética de la convicción y de la responsabilidad en tanto encarna el enfrentamiento al Estado en nombre de otra ley superior y lleva su resistencia y el no ceder hasta la muerte misma. Onfray afirma que "la resistencia puede ejercerse en todos los órdenes frente a un poder que funciona sobre el principio de las categorías teológicas de omnipresencia, omnipotencia, incluso omnisciencia [...] Sea cual fuere el poder, la función del individuo consiste en oponer una resistencia determinada, una insumisión tenaz a lo que exige la autoridad” (171173).

5 Me he ocupado de sus novelas policiales, en especial de Sombra de la sombra, en el capítulo "El crimen a veces paga. Policial latinoamericano en el fin de siglo” de mi libro Juegos de seducción y traición.

6 Autor asimismo de un libro de memorias de la guerra civil organizado por la oposición "perdedor vs. vencedor”: Para parar las aguas del olvido.

7 Varias de las notas y artículos de la colección están dedicadas a establecer sus filiciones y preferencias literarias. Veánse en especial "Esas novelas negras...” o "Ilán, supongo que conservas...”

Revista Iberoamericana, Vol. LXXX, Núm. 247, Abril-Junio 2014, $353-371$
ISSN 0034-9631 (Impreso) 
derrotada" el autor se incluye entonces doblemente, como heredero de su padre y, por ende, de la guerra civil española y como miembro de su desencantada generación mexicana.

En realidad, se podría construir un pequeño “corpus Taibo” dedicado al perdedor, si incluimos otros dos textos, un relato, Héroes convocados, publicado en 1982 y un "híbrido", mezcla de ensayo y memoria personal, 68, de 1991. El conjunto abarca suficientes años como para pensar en una recurrencia casi obsesiva (teniendo en cuenta sus novelas, ensayos y biografías) y constituye una "saga” personal en torno al perdedor; se trata posiblemente del corpus más amplio y coherente de un único autor, concentrado en una coyuntura muy específica como es la derrota del 68 en México. Ambos textos, Héroes convocados y 68, son complementarios, la ficción tiene la tradicional función consoladora que proporcionaba la novela de aventuras, es así un intento de paliar el desconsuelo, la nostalgia, que se confiesa en 68. Estas memorias se escriben, según dice el autor, para reemplazar una novela que "nunca pude escribir [...] Probablemente es una novela que no quiere ser escrita" (11). Sin embargo, esa novela existe y fue escrita casi 10 años antes, podríamos entonces pensar que ambas son dos versiones en torno a la derrota: Héroes convocados juega con la ilusión de recuperar la justicia, con otro final para la derrota gracias a los héroes de las novelas de aventuras, aquellas que siempre "tienen final feliz" y cuyo protagonista es capaz de restablecer el triunfo de los "buenos". El relato está armado por diversos fragmentos e incluye las cartas que los amigos envían al protagonista con las versiones de lo ocurrido en el '69 (“el año de la derrota”) en el movimiento estudiantil, luego de la matanza de Tlatelolco en octubre del 68. El personaje, internado en un hospital, sueña -desea, alucina- con la convocatoria a sus héroes de la infancia: Sandokán, los Tigres de la Malasia, Sick Turpin, Sherlock Holmes, los Tres Mosqueteros y muchos más. Ellos acuden a México llamados por este "miembro de la generación de los derrotados" (68) para restablecer la justicia "porque no podía haber tanto desencanto, tanta derrota" (61). Sin embargo, los héroes serán exiguos, construidos con el material de los sueños y los protagonistas "reales” confirmarán su derrota en la dispersión y el desaliento. El "apéndice número dos" corresponde al autor mismo que cierra las capas de ficción encuadrándolas en su presente mexicano; sus palabras ("nos fueron acabando como generación [...] el sueño subterráneo de los que vivimos el 68 zozobraba y se hundía en el reflujo” [122]) establecen el vínculo con el texto de 1991, esas memorias personales que son "la versión en otro género" de la misma historia. Años después, el movimiento del 68 es un fantasma que va perdiendo corporeidad; sin embargo, esa condición fantasmática no significa olvido ni claudicación:

Buena parte de los que entonces fuimos, seguimos vivos [...] La mayoría no acumuló más derrotas en la vida que las que les impusieron. Derrotas, un chingo, pero bastante pocas rendiciones [...] por ahí andamos cargando los fantasmas de nuestros muertos, los fantasmas de nuestros escasos traidores, los fantasmas de nuestros suicidas [...]

\footnotetext{
Revista Iberoamericana, Vol. LXXX, Núm. 247, Abril-Junio 2014, 353-371 ISSN 0034-9631 (Impreso) ISSN 2154-4794 (Electrónico)
} 
descubro que parecemos condenados a ser fantasmas del 68 [...] Mucho mejor condes Dráculas de la resistencia, quemonstruos priístas de Frankenstein.(114-116, énfasis mío).

Entre uno y otro texto se ha renunciado a la esperanza de ser héroe, se ha perdido la ilusión de contar con Sandokán, dejar de ser perdedor y hacer justicia, pero han perdurado la memoria y la capacidad de resistencia.

Puede ser interesante poner en contacto a Taibo y su modo de relacionarse con la derrota que implica esa coyuntura histórica para México, con un texto de Luis González de Alba, uno de los dirigentes del movimiento estudiantil de 1968. En un ensayo muy posterior, Las mentiras de mis maestros, reúne texto e historieta en un intento de analizar, con tono irónico, desencantado y humorístico, la identificación de la historia mexicana con los vencidos y no con los vencedores. Se abre con el capítulo "La visión de los vencidos" que remite de inmediato a la recopilación del mismo nombre de las relaciones indígenas de la conquista hecha por León-Portilla; y se cierra con un "Epílogo desencantado" cuyas últimas palabras son "sólo nos resta enfrentar, con Cioran, 'la pericia de la decepción”” (272). La historia mexicana aparece así como “una larga serie de derrotas gloriosas y un pesado directorio de héroes derrotados" (110) debido a que se venera la caída y el fracaso es símbolo de pureza. Desencanto y decepción cierran el libro, pero la pérdida de las ilusiones se convierte en el fantasma de un fracaso y, en este caso, no se asimila al orgullo del perdedor ético. Lejos de éste, el autor opta por un registro irónico y burlón, que se refuerza con los chistes gráficos, con el que se distancia y ridiculiza esta "vocación perdedora”.

González de Alba había publicado en 1971 Los días y los años, una crónica de los acontecimientos de Tlatelolco y del conflicto que lo llevó a la cárcel. Escrita en Lecumberri, en su párrafo final leemos: "sólo queda el destello breve de la libertad que no conocíamos hasta que vivimos esos días [...] la sensación de estarlo cambiando todo, de colaborar [...] para cambiarlo todo” (207). Quizá no sea casual que en Las mentiras de mis maestros el mismo autor sostenga treinta y un años después: "Los humanos hemos pasado una buena parte de nuestra historia proponiendo utopías maravillosas, padeciendo los resultados y añorando luego -arrepentidos del ensayo libertario- la antigua tiranía derrocada" (257). Quizás tampoco sea casual que proponga entonces un regreso al orden y a los pactos en los que el fracaso es visto como una vocación por el desorden opuesto al éxito ejemplar del imperio dominante. Ambos libros, el de Taibo y el de González de Alba, representan dos modos de resolución opuestos para resolver la dolorosa derrota de los años sesenta: resistencia o bien desencanto y distanciamiento constituyen dos vertientes que se reiteran también de modo diverso en las representaciones ficcionales.

Dos novelas mexicanas de los comienzos del nuevo milenio resumen y extreman hasta el cinismo-al menos en el primer caso-la experiencia de la pérdida como decepción de las utopías políticas expuesta por González de Alba; ambas se juegan a representar

\footnotetext{
Revista Iberoamericana, Vol. LXXX, Núm. 247, Abril-Junio 2014, 353-371 ISSN 0034-9631 (Impreso) ISSN 2154-4794 (Electrónico)
} 
una época histórica que atraviesa la vida de los protagonistas y sobre la que se hace un "balance y ajuste de cuentas". Precisamente, el uso de la historia para el anclaje de la trama en coyunturas políticas muy emblemáticas (el mayo francés, la caída del muro de Berlín) permite que los personajes funcionen como sinécdoques de esas situaciones históricas que dramatizan. Ambas, finalmente, se presentan como formas de escritura en las que múltiples voces debaten sobre la validez de la resistencia o la fe en cualquier clase de utopía. De hecho, y en la medida en que el desencanto político se vuelve radical y afirma lo inútil que es persistir en las pasadas utopías, "la voz" del texto, se desliza de las posiciones del perdedor sin ilusiones a una afirmación tácita de los espacios del vencedor. Este lugar termina por ser el único posible, el aceptado desde un razonable presente en el que las "viejas creencias" o la resistencia no son más que inflexiones de la sinrazón, de la locura.

Precisamente, El fin de la locura de Jorge Volpi es una de las novelas que en los comienzos del nuevo siglo hace de la desilusión frente a la pérdida de los proyectos sesentistas su eje narrativo. Enmarcada por dos cartas fechadas en 1989 (en el momento de la caída del muro de Berlín), la trama retrocede a 1968 y va pasando por los episodios -el mayo francés-y los protagonistas -Lacan, Foucault-claves en el mundo intelectual de los sesenta; a su vez, este pasaje está atravesado por una mirada irónica que va “socavando" la legitimidad y el sentido de los proyectos y creencias de esos años.

La carta que abre el texto, cronológicamente posterior a la que lo cierra, intenta un balance de la vida de Aníbal Quevedo, protagonista:

[E]ncarno el fracaso de tus ilusiones [...] Dequéte sirvió contemplar el fin de la revolución, el penoso trayecto de este siglo, el sanguinario envejecimiento de nuestra causa? $\mathrm{Si}$ algo aprendimos en esta era de dictadores y profetas, de carniceros y mesías, es que la verdad no existe: fue aniquilada en medio de promesas y palabras. (12, énfasis mío)

Mientras que la carta de cierre pertenece a la figura femenina, Claire, su antagonista ideológica, y permite definir al personaje de Quevedo como un paradigma de la capacidad de transacción:

No sé si tu connivencia con el poder es voluntaria o producto de un desliz o una conjura: simplemente no tolero la posibilidad de que hayas transigido [...] Recuerdo tus últimas palabras: [...] 'Ya no son los mismos tiempos de antes, Claire, cuando éramos jóvenes y creíamos en la revolución. Ahora, para seguir adelante y preservar nuestra lucha, debemos ser realistas.' [...] en vez de resistir, negociabas. [Yo] nunca transijo. Lo siento, Aníbal: a diferencia de ti, yo no pienso renunciar a la locura. (462, énfasis mío)

Entre estas dos cartas, totalmente explícitas en sus posiciones político-ideológicas -e incluso ejemplares para el sistema de mi corpus- se desarrolla el relato. Si bien a

\footnotetext{
Revista Iberoamericana, Vol. LXXX, Núm. 247, Abril-Junio 2014, 353-371 ISSN 0034-9631 (Impreso) ISSN 2154-4794 (Electrónico)
} 
lo largo de la novela el lector es testigo de la lucha entre las dos posturas antagónicas allí representadas (lucha que podría pensarse como un juego de equilibrios entre la desilusión y la resistencia), la voz del texto se inclina de modo evidente hacia una de las posiciones. En efecto, el título mismo determina cómo calificar el "fracaso de las ilusiones": "fin" parece clausurar toda posibilidad utópica y "locura” reduce los proyectos políticos y su debate al espacio de lo irracional y lo absurdo; éste es el punto clave donde se distancia de los relatos con perdedores éticos que resisten. Del mismo modo funcionan muchos de los títulos y subtítulos de las dos partes en que se divide la novela: "Si Althusser permanece en cura de sueño, el movimiento de masas va bien" (119) o "Una utopía tropical” (191). Los epígrafes atribuidos a figuras emblemáticas de los años sesenta -Lacan, Althusser, Barthes, Foucault- buscan el mismo efecto de "insensatez" al estar sacados de contexto, no establecer ningún vínculo con lo que se narra a continuación o producir un efecto cómico. ${ }^{8}$

A su vez, la bibliografía que cierra la novela tiende a producir un efecto de solidez, de seguridad informativa; una información que parece volver convincente la trama y la perspectiva del relato. ${ }^{9}$ Se trabaja sobre un saber y una complicidad con el lector, su conocimiento de una época y de los textos que la representan: la novela intenta una estrategia -a la que mucho contribuyen la sucesión de epígrafes y la larga cadena de citas "sin sentido"- destinada a minar el discurso de aquellas figuras que construyeron el pensamiento político y utópico de esos años, los íconos de los jóvenes de los sesenta. Estos elementos definen la posición del texto mas allá del protagonista y narrador, esa figura ambigua, a quien el duelo ideológico con Claire también lo muestra desencantado hasta el cinismo:

\begin{abstract}
Yo me esforzaba por memorizar las infinitas variantes de la utopía revolucionaria -el proceso no era muy distinto a aprender las jerarquías de los ángeles o los círculos del infierno-, pero al final siempre me doblegaba la jaqueca. (133)

Sébastien encarnaba el modelo del revolucionario-y del neurótico-perfecto: comparado con él, yo apenas era una burda caricatura de intelectual comprometido. (135)
\end{abstract}

Claire, paradigma de la posición utópica (“no pienso renunciar a la locura”) se encuentra frente al narrador en la misma situación que el lector: cómo no dudar de alguien sospechoso de traición y tratos con el poder, que puede ser acusado "de ser no sólo un impostor sino un delincuente” por algunos, mientras "otros lo consideran uno

8 Es ejemplar el epígrafe que abre el primer capítulo: "Si ustedes creen haber comprendido, de seguro se han equivocado. Lacan, El seminario, libro I” (19).

9 La misma función, remitir a lo real, podría tener la irónica nota ("Este libro es una obra de ficción. Cualquier semejanza con la realidad es culpa de esta última”) que abre el relato junto con dos citas, una de Flaubert y otra de Cervantes: en ambas están presentes los términos locura, escepticismo y melancolía.

ISSN 0034-9631 (Impreso) 
de los intelectuales mexicanos más importantes del siglo XX” (456). ¿Se trata de un perdedor, de un fracasado o de un "héroe de nuestro tiempo"? Sin duda se ha diluido en él toda "responsabilidad ética": sus comentarios, sus declaraciones, el proyecto de un coloquio llamado "Las desventuras de la revolución”, lo señalan como un perdedor que se ha ido acomodando al "aire de los tiempos”, no está dispuesto a seguir siendo fiel a las “antiguas locuras” e, indudablemente, se encuentra cómodo cerca del espacio de los triunfadores. ${ }^{10}$

En un primer momento, el lector puede pensar que la escritura misma oscila en la ambigüedad o ironiza y descalifica al personaje; sin embargo, la coincidencia entre sus declaraciones y la organización del texto, de los títulos y epígrafes, lo llevarán a la conclusión de que la novela, más que una reflexión o balance de las derrotas, las descalifica a partir de vincularlas con la locura y el sinsentido. Es interesante que una reseña, escrita por un enemigo del protagonista y titulada “Peor libro del año", a El fin de la locura de Aníbal Quevedo, “con edición a cargo de Jorge Volpi”, anticipe algunas de las críticas que el lector podría hacer al texto que leemos:

Por enésima vez, asistimos al relato de la azarosa vida de un escritor latinoamericano de izquierdas en París que nos conduce, tras una serie de aventuras a cual más inverosímil, hasta su forzado regreso a México [...] Se requeriría una paciencia ilimitada para establecer qué capítulo es peor: el psicoanálisis de Fidel Castro (!), [...] su encuentro filosófico en la Selva Lacandona con el ineludible subcomandante Marcos [...] ¿Qué pretende el autor de un libro como éste? ¿Realizar un balance de ese lamentable error de cálculo que conocemos como izquierda? [El lector quedará] decepcionado por el escaso interés del libro, por el patético final de su personaje y por todos esos ilusos que alguna vez trataron de cambiar al mundo. (452, énfasis mío)

En esta puesta en abismo, el narrador ficticio y el autor real han escrito un libro con el mismo nombre, que contiene la misma historia y por lo tanto son susceptibles de recibir las mismas críticas. Sin embargo, la reseña fue escrita por un enemigo que persigue con saña al narrador y, de este modo, el texto vuelve a jugar con la ambigüedad: este crítico ¿habla desde el resentimiento? ¿Quién es en verdad el más “decepcionado por los ilusos que trataron de cambiar el mundo”? ¿El crítico? ¿el autor Aníbal Quevedo?

\footnotetext{
${ }^{10}$ Es interesante que en el capítulo "Corre, camarada, que el viejo mundo está tras de ti” diga el narrador a propósito de la matanza de Tlatelolco: “iQué estupidez! ¿Cómo se les ocurrió a esos muchachitos que en México podría reproducirse el Mayo francés?” (141). Sin embargo, él mismo intentará hacer en México la revista Tal Cual, una copia, al menos en el título, de Tel Quel, la mítica revista de los años sesenta en la que participaron la mayoría de los intelectuales posestructuralistas mencionados en la novela. Parece ser posible para el protagonista el gesto snob de un "transplante" intelectual, a la vez que no alcanza a comprender el sentido político específico del movimiento estudiantil mexicano.
}

Revista Iberoamericana, Vol. LXXX, Núm. 247,
ISSN 0034-9631 (Impreso) 
¿el lector? Los espacios de enunciación son móviles, lábiles y parecen no definir nunca donde está la voz del texto, sólo la semejanza entre las estrategias de los “dos relatos", entre la posición del personaje narrador y el sujeto de enunciación textual, abren la posibilidad de rastrear las coincidencias entre ambas voces.

México vs. Berlín; otra vez los hechos políticos claves de la historia más o menos reciente entramados con la ficción, nuevamente un relato que funciona como memorias de juventud, narrado desde el punto de vista de uno de los protagonistas (tres latinoamericanos -mexicano, brasileño y colombiano-becados en el Berlín de los años sesenta, "representantes" de estereotipos ideológicos) y con la misma oscilación de las voces entre el desencanto por lo perdido, la desilusión y la resistencia: Tu nombre en el silencio de José María Pérez Gay parece un compendio de los rasgos mencionados para la novela de Volpi y, en este sentido, produce un efecto de déjà vu. Si el narrador de El fin de la locura propone un coloquio llamado "Las desventuras de la revolución”, Tu nombre en el silencio se abre con el regreso a Berlín del mexicano para asistir a otro coloquio, titulado "Los años ochenta: la década perdida para América Latina”. Pérdidas y desventuras son el centro de la experiencia en los dos casos.

El relato transcurre con el telón de fondo de la revuelta estudiantil en Alemania y de las derrotas políticas en tres países latinoamericanos: el caos de Colombia, el México del '68, la dictadura de Brasil. Los tres personajes funcionan nuevamente como sinécdoques de cada una de esas historias de pérdida: sus vidas están ligadas al fin de las ilusiones, a los modos en los que las utopías se destruyen y se olvidan; por consiguiente, el eje del relato se enfoca en cómo se sobrevive (o no) a esa experiencia. El regreso al pasado y al espacio de ese pasado -Berlín-le permite a Ernesto Cardona, el protagonista mexicano, “establecer un inventario de las pérdidas” (13) desde aquella época de utopías hasta el presente de desilusión o fracaso. Es sintomático que vaya al congreso sin ponencia ("no tengo nada que decir" [21]) y no crea en la consigna del encuentro: "no creo que los años ochenta hayan sido la década perdida, más bien creo que el siglo xx es uno más de los siglos perdidos para América Latina” (21).

Si la primera parte de la novela es la rememoración de aquellos años de esperanzas revolucionarias a través del relato puntual de episodios históricos en los que están envueltos los tres jóvenes, la última va registrando en qué ha quedado toda esa esperanza. Cada uno de ellos ha experimentado alguna forma de la derrota: sin duda el caso más extremo es el del personaje brasileño que muere de forma absurda bajo las balas de la dictadura de su país, a pesar de descreer, como él mismo había admitido, de cualquier forma de utopía: "el fervor de los sueños no nos sirve para nada. Nuestra inteligencia puede ponerse al servicio de la estupidez, cuando es tan profunda la necesidad de una ilusión” (457).

\footnotetext{
Revista Iberoamericana, Vol. LXXX, Núm. 247, Abril-Junio 2014, 353-371 ISSN 0034-9631 (Impreso) ISSN 2154-4794 (Electrónico)
} 
En "el inventario de las pérdidas" desfilan personajes históricos, como Rudi Dutschke, ${ }^{11} \mathrm{y}$ ficticios; es interesante, ya en el cierre del texto, el encuentro en Nicaragua entre los dos amigos que han quedado vivos, el colombiano, que está participando del proyecto revolucionario, y el mexicano. El diálogo entre los dos es el resumen final y muy explícito de las dos perspectivas en las que oscilan los personajes (y la escritura misma); ambos encarnan también dos paradigmas, el resistente que no ceja en sus creencias y el escéptico que optó por la vida de académico desencantado:

-¿Qué haces aquí, colombiano? ¿Tú crees que Nicaragua tiene una salida?

-Aquí todas las derrotas anteriores cobran un sentido. Hay que defender Nicaragua como no defendimos Chile. [...]

-Esta no es tu guerra, colombiano. Márchate y camina sin voltear atrás [...]

Cuídate, colombiano, no te pongas en peligro, no hay Numancia que valga la pena. (509-516)

Entre la "opción que vale la pena” de Dutschke (citada en la nota 11) y el "no hay Numancia que valga la pena” del protagonista se despliegan los diversos modos que implica aceptar la pérdida de la utopía: ya sea proponer otro camino, moderado, para la acción, persistir sin desmayo y contra toda lógica -como el personaje colombiano-, o entregarse al desencanto del mexicano. El epílogo cierra la historia en el Berlín de 1990 (luego de la caída del muro) y recoge los destinos de todos los protagonistas: si la muerte de Nuno, el brasileño asesinado en 1970 por un comando paramilitar en plena dictadura, fue una muerte sin sentido (que no valió la pena), la continuidad en la lucha del amigo colombiano tampoco tuvo un final feliz, en la medida en que el lector sabe cómo se diluyó la revolución en Nicaragua. De algún modo, el texto “da la razón” al personaje mexicano, desde cuya perspectiva se desarrolla toda la novela hasta su visita final al pueblo, ahora desierto, donde transcurrieron sus vidas de estudiantes; un lugar que lo lleva a evocar una cita de Celan ("pon tu bandera a media asta,/ Memoria,/ a media asta, hoy y siempre” [523]) y el epitafio de la tumba de León Halévy (“Cómo has podido dejar tu nombre en el silencio" [523]). Olvido, silencio y nostalgia cierran aquel "inventario de las pérdidas" que el mismo protagonista propuso al comienzo de la narración; sin duda es allí, en ese espacio fantasmal, donde concluye su duelo por un mundo y un proyecto desvanecido. Queda entonces en él solamente el melancólico recuerdo de lo perdido, de algo que permanecerá definitivamente en el pasado y nada tiene que ver con su presente.

${ }^{11}$ Figura histórica central al texto que sigue cuidadosamente su vida: es uno de los representantes más conocidos del movimiento estudiantil de los años sesenta en Alemania Occidental. En 1968 fue víctima de un atentado de un joven de ultraderecha; a pesar de la gravedad de sus heridas, sobrevivió y murió en Dinamarca en 1979. En la novela, se lo ubica, ya al final de su vida, en el Partido Verde diciendo: "No será el gran proyecto socialista, pero es la única opción que vale la pena” (501).

Sinf Revista Iberoamericana, Vol. LXXX, Núm. 247, Abril-Junio 2014, 353-371 ISSN 0034-9631 (Impreso) ISSN 2154-4794 (Electrónico) 
En una vía muy distinta y más cercana a la propuesta por la narrativa de Taibo II, la novela de Jordi Soler, Los rojos de ultramar, hace del cruce entre memoria y derrota su eje narrativo y, a la vez, fusiona dos espacios histórico-geográficos reuniendo en el debate varias líneas de las "dos orillas”. Los rojos... narra el destino de un grupo de perdedores españoles exilados en México desde el presente de una escritura que se propone reconstruir aquel pasado, la historia de un abuelo, es decir, una genealogía. La búsqueda de la verdad y la lucha contra el olvido sostienen la historia que surge a partir de unas memorias escritas por el abuelo del narrador; la novela es el relato de la investigación en busca de los hechos olvidados y se plantea como una escritura a partir de la pérdida. La escritura cubre entonces la ausencia, el olvido, la pérdida de la patria: recompone la memoria incompleta, la historia acallada, se origina así en la carencia y en los fragmentos, ocultos durante medio siglo del diario del abuelo. Es entonces, también búsqueda de una identidad y de un anclaje entre dos mundos ligados por el exilio. ${ }^{12}$ Dos escenas en el primer capítulo fundan esa escritura: la primera, en México, es el relato de "cinco ex combatientes republicanos que décadas después de haber perdido la guerra, en plenos años sesenta, desde su trinchera en la selva de Veracruz, seguían batallando contra el general Franco" (13) que le entrega el abuelo al protagonista. La otra escena transcurre en Madrid, en la Universidad, donde el mismo personaje comprueba el desconocimiento que los estudiantes tienen del exilio y la persecución franquista: ambos han sido borrados de la historia oficial de España. Esa conjunción de escritura y olvido desencadena el relato del nieto, su obsesiva búsqueda de los hechos; el protagonista de Los rojos de ultramar tratará de reconstruir la historia de su abuelo yendo más allá de lo que ha dejado escrito. Expurgar esa escritura para ampliarla, hacerla más completa, entender, sacar a la luz lo que ha permanecido oculto llevará a la propia investigación de lo ocurrido. De algún modo, lo señala el narrador de Los rojos de ultramar: "haber heredado una guerra perdida había interferido en nuestra forma de mirar el mundo" (175). Por ese motivo inicia un viaje hacia el pasado para conocer el campo de concentración en el que estuvo su abuelo, un espacio que parece borrado, que no está en ninguna parte, ni siquiera en los folletos y los textos de la historia del lugar, donde ha prevalecido la voluntad de olvido. No quedan vestigios de los republicanos, el único rastro del campo es un poste semioculto, una ruina donde el protagonista deja un bolígrafo: ante la ausencia y la falta de memoria deja "[su] rastro y [su] presencia” (185), clava en el ámbito de la muerte el medio material con el que producirá la escritura reparadora. A partir de ese momento, luego de su paso por ese espacio sin recuerdos donde se ha escamoteado la muerte, el narrador podrá escribir y completar la historia,

${ }^{12}$ Los epígrafes acentúan la relación identidad/genealogía/memoria: el poema de Luis Cernuda (“Como esta vida que no es mía/Y sin embargo es la mía/Como ese afán sin nombre/Que no me pertenece y sin embargo soy yo") y el de W.B.Yeats (“And what if my descendents lose the flower”).

Revista Iberoamericana, Vol. LXXX, Núm. 247, Abril-Junio 2014, 353-371
ISSN 2154-4794 (Electrónico) 
asumirla como propia y encontrar la clave oculta; lo omitido en el relato de su abuelo será una historia que lo define a él y a sus amigos exilados: el proyecto de asesinar a Franco. El fracaso de este plan imposible es el comienzo de la transformación de los viejos perdedores que han quedado suspendidos entre dos mundos, ya no pertenecen a ninguno por completo y mientras Franco celebra los veinticinco años de su triunfo se desmorona el equilibrio que sostenía la utopía del regreso. ${ }^{13}$ La identidad del perdedor comienza a cambiar en la medida en que ya no encuentra sentido en la resistencia; el regreso a España, luego de la muerte de Franco, será una nueva forma del fracaso. Las diferencias con el pasado recordado se condensan en la lengua: "el catalán que había preservado [...] y que había transmitido a dos generaciones, era una lengua contaminada, híbrida, con un notorio acento del ultramar” (228, énfasis mío). A partir de ese viaje en que el "regreso a casa" implica la vuelta a México, se produce un viraje, la condición de perdedor que resiste se transforma y genera el repliegue, una especie de claudicación, de "volverse otro", que comenzó en aquel lejano campo de concentración y culmina cuando ya no cabe esperar nada luego del largo exilio sin salida:

El repliegue de Arcadi tenía que ver con su capitulación, con su retirada, era la representación de la derrota, en el fondo se parecía al repliegue de los miles de individuos que vivieron la guerra y que, puestos frente a la memoria de aquel horror, decidieron, como él, replegarse, darle la espalda [...] pensar que esa guerra había sido peleada por otros, en un lugar y tiempo tan remotos [...] que unas cuantas décadas más tarde, apenas queda memoria de esa guerra. (234, énfasis mío)

El personaje se ha vuelto otro, su identidad cambia y comienza la decadencia que lo vuelve un extraño con respecto a su condición de perdedor: Los rojos... dramatiza uno de los posibles “finales” para los antihéroes de los relatos de resistencia. No parece casual que la novela haya sido escrita por un latinoamericano, un mexicano, sobre el exilio español: la distancia y el tiempo transcurridos permiten un balance o vislumbrar posibles finales a las historias de derrota desde el presente del narrador. La aceptación de la pérdida, que no tendrá vuelta atrás a pesar de las viejas esperanzas y los años de resistencia, a pesar de saber bien que resistir y recordar es la única forma de triunfo digno sobre los vencedores, funciona en esta novela de 2005 como un "balance de la derrota”, una especie de espejo de anticipación para los perdedores latinoamericanos.

${ }^{13}$ Este proyecto frustrado, así como el desencanto frente al regreso, es una indudable alusión al escritor español exilado en México Max Aub, en especial a su cuento "La verdadera historia de la muerte de Francisco Franco" en el que un mozo mexicano del bar en que se reúnen los exilados, cansado de oírles hablar siempre de la guerra perdida, decide ir a España con el propósito de matar a Franco. Lo consigue, pero no logra que regresen y dejen de contar sus historias: bajo el aparente humor del argumento corre la desolada convicción de una derrota sin remedio.

ISSN 0034-9631 (Impreso) 
Se trata aquí de un desenlace mucho más doloroso, de la resignación del perdedor que ha resistido pero finalmente parece aceptar la inutilidad de su lucha porque ha reconocido lo irreversible de la derrota, pero que no ha transado jamás. Esta pérdida, frente a la cual es mejor el repliegue final, volverse otro, olvidar la lucha sostenida por tantos años construye la melancólica imagen final de la novela:

Le conté que había estado releyendo sus memorias y oyendo las cintas que habíamos grabado y que la idea de hacer algo con todo eso empezaba a entusiasmarme. Mira que eres necio, me dijo, eso fue todo. Después me miró extrañado, como si no me reconociera, y luego volvió al plato de huevos revueltos que se estaba comiendo con la mano. (235)

Pero si bien el texto representa esta dolorosa inflexión de la pérdida, el derrumbe sin consuelo de aquél que sostuvo la esperanza más allá de toda razón, también propone a la escritura como reparadora de ese olvido, de la omisión de la historia. La novela que leemos es el resultado de esa voluntad de memoria, es la lucha por superar la desmemoria que el narrador asume como propia desde el comienzo.

Es interesante que la literatura proponga un debate ausente-en especial en América Latina- en la mayoría de los discursos políticos que le son contemporáneos; quizá esto es porque ella "se sitúa frente a la historia como la otra cara de la luna” (16), según afirma Claudio Magris en Utopía y desencanto; es decir, se hace cargo de las cuestiones más polémicas y obliga a enfrentar dilemas tan complejos como los que plantea la aceptación de una derrota y sus consecuencias. La ficción española contemporánea de la latinoamericana, por el contrario, más distante de las derrotas que narra, forma parte de una discusión presente en múltiples discursos, históricos, mediáticos, académicos. Es posible que la lejanía temporal, los múltiples y fallidos intentos de olvido, las nuevas condiciones políticas, hayan hecho posible este resurgir de las figuras de los perdedores.

Mi trabajo trató de diseñar una red, establecer una constelación de textos vinculados por sus representaciones de la experiencia de derrota; entre ellos puede haber notables distancias, pueden establecerse diferencias que van de la sutileza y complejidad de autores como Borges a los poco mediatizados y un tanto obvios usos de la historia de relatos como El fin de la locura de Volpi. El pasaje por textos tan diversos y el balance de esas experiencias perdedoras despliega distintas "lógicas” que la literatura ha propuesto, imaginado, más allá de las vigentes en nuestro mundo cotidiano. El aprendizaje que sobreviene a la derrota implica sin duda la necesidad de asumir posiciones, de elegir entre “un abanico de posibilidades”, de opciones políticas. Podemos pensar que los textos -muy especialmente los que se enfocan en la figura del perdedor ético- intentan "una configuración distinta” a la dominante en los noventa y el fin del siglo, anticipan otras formas de pensar la derrota y la política. Sus protagonistas se debaten entre una ética de la responsabilidad o de la convicción, entre distintas formas de poder y de prácticas

Revista Iberoamericana, Vol. LXXX, Núm. 247, Abril-Junio 2014, $353-371$
ISSN 2154-4794 (Electrónico) 
políticas, entre la memoria y el olvido. Desde los antihéroes derrotados, con su capacidad de resistencia y su orgullosa aceptación de la derrota, hasta los decepcionados, cínicos o melancólicos que se han rendido a "la evidencia de los hechos”, a través de traidores, vencedores y desencantados, un amplio corpus narrativo presenta alternativas y, a la vez, toma posición ante ellas. Probablemente las más utópicas, las más irreductibles, las más improbables, son aquellas que de haber sido llevadas a la práctica en nuestro mundo real, habrían paliado en parte el dolor de tantas derrotas, habrían, en suma, construido otra historia.

\section{BiBLIOGRAFÍA}

Adorno, Theodor W. Minima moralia. Reflexiones desde la vida dañada. Obra Completa, 4. Madrid: Akal, 2004.

Agamben, Georgio. Medios sin fin. Notas sobre la política. Valencia: Pre-textos, 2001.

Amar Sánchez, Ana María. Instrucciones para la derrota. Narrativas éticas y políticas de perdedores. Barcelona: Anthropos, 2010.

Juegos de seducción y traición. Literatura y cultura de masas. Rosario: Beatriz Viterbo, 2000.

Aub, Max. La verdadera historia de la muerte de Francisco Franco. Barcelona: Seix Barral, 1979.

Avelar, Idelber. Alegorías de la derrota: la ficción postdictatorial y el trabajo del duelo. Santiago: Cuarto Propio, 2000.

Badiou, Alain. L'éthique. Essai sur la conscience du mal. Caen: Nous, 2003. Reflexiones sobre nuestro tiempo. Buenos Aires: Del Cifrado, 2000. ¿Se puede pensar la política? Buenos Aires: Nueva Visión, 1990.

Bobbio, Norberto. Teoría general de la política. Madrid: Trotta, 2005.

Esposito, Roberto. Categorías de lo impolítico. Buenos Aires: Katz, 2006. Confines de lo político. Madrid: Trotta, 1996.

Foucault, Michel. Historia de la sexualidad, I. México: Siglo XXI, 1978.

González de Alba, Luis. Las mentiras de mis maestros. México: Cal y Arena, 2002. Los días y los años. México: Era, 1971.

León-Portilla, Miguel. Visión de los vencidos. Relaciones indígenas de la conquista. México: Universidad Nacional Autónoma de México, 1959.

Magris, Claudio. Utopía y desencanto. Barcelona: Anagramas, 2001.

Onfray, Michel. Política del rebelde. Tratado de la resistencia y la insumisión. Buenos Aires: Perfil, 1999.

Padura, Leonardo. La neblina del ayer. México: Tusquets, 2005.

Pérez Gay, José María. Tu nombre en el silencio. México: Alfaguara, 2006.

Piglia, Ricardo. Respiración artificial. Buenos Aires: Pomaire, 1980.

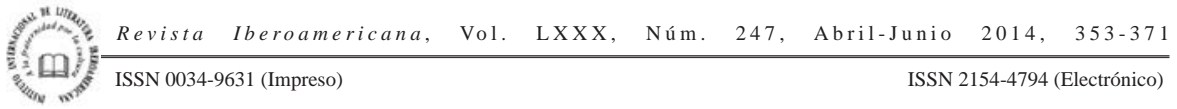


Rancière, Jacques. El viraje ético de la estética y la política. Santiago: Palinodia, 2005. Sobre políticas estéticas. Barcelona: Universitat Autonoma, 2005.

Said, Edward. Representaciones del intelectual. Barcelona: Paidós, 1996.

Sasturain, Juan. Manual de perdedores. Barcelona: B, 1998.

Soler, Jordi. Los rojos de ultramar. Mexico: Alfaguara, 2005.

Taibo I, Paco Ignacio. Para parar las aguas del olvido. México: B, 2005.

Taibo II, Paco Ignacio. 68. México: Planeta, 1991.

Arcángeles. Doce historias de revolucionarios herejes del siglo XX. México:

Planeta, 1998.

Héroes convocados. México: Grijalbo, 1982.

Primavera pospuesta. Una versión personal de México en los 90. México: Joaquín Mortiz, 1999.

Schmitt, Carl. El concepto de lo político. Madrid: Alianza, 1991.

Volpi, Jorge. El fin de la locura. Barcelona: Seix Barral, 2003.

Weber, Max. Ciencia y política. Buenos Aires: CEAL, 1991.

Revista Iberoamericana, Vol. LXXX, Núm. 247, Abril-Junio 2014, 353-371
ISSN 2154-4794 (Electrónico) 
